\title{
A study on the expression of apoptotic molecules related to death receptor and endoplasmic reticulum pathways in the jejunum of $\mathrm{AFB}_{1}$-intoxicated chickens
}

\author{
Zhixiang Zheng ${ }^{1,2, *}$, Zhicai Zuo ${ }^{1,2, *}$, Panpan Zhu ${ }^{1,2, *}$, Fengyuan Wang ${ }^{1,2, *}$, Heng Yin ${ }^{1,2}$, \\ Xi Peng ${ }^{3}$, Jing Fang ${ }^{1,2}$, Hengmin Cui ${ }^{1,2}$, Caixia Gao ${ }^{1,2}$, Hetao Song ${ }^{1,2}$, Ping Ouyang ${ }^{2}$, \\ Yi Zhou ${ }^{4}$ and Song Zhao ${ }^{1,2}$ \\ ${ }^{1}$ Key Laboratory of Animal Diseases and Environmental Hazards of Sichuan Province, College of Veterinary Medicine, Sichuan \\ Agricultural University, Chengdu, Sichuan 611130, PR China \\ ${ }^{2}$ College of Veterinary Medicine, Sichuan Agricultural University, Chengdu, Sichuan 611130, PR China \\ ${ }^{3}$ College of Life Sciences, China West Normal University, Nanchong, Sichuan 637002, PR China \\ ${ }^{4}$ Life science department, Sichuan Agricultural University, Yaan, Sichuan 625014, PR China \\ *These authors have contributed equally to this study \\ Correspondence to: Jing Fang, email: fangjing4109@163.com \\ Xi Peng, email: pengxi197313@163.com
}

Keywords: aflatoxin $B_{1}$, apoptosis, jejunum, death receptor molecules, endoplasmic reticulum molecules

Received: April 28, $2017 \quad$ Accepted: June 16, $2017 \quad$ Published: August 18, 2017

Copyright: Zheng et al. This is an open-access article distributed under the terms of the Creative Commons Attribution License 3.0 (CC BY 3.0), which permits unrestricted use, distribution, and reproduction in any medium, provided the original author and source are credited.

\section{ABSTRACT}

Aflatoxin $B_{1}\left(A F B_{1}\right)$ is a common contaminant of poultry feeds in tropical and subtropical climates. Early researches have well established the hepatotoxic, carcinogenic, and immunotoxic effects of AFB $_{1}$ on humans and animals. Recently, it has been shown that $\mathrm{AFB}_{1}$ could cause the up- or down-alteration of mitochondrial pathway molecule expression. However, the information on the expression of death receptor and endoplasmic reticulum molecules in the jejunal apoptosis induced by AFB $_{1}$ were unavailable. So the present study was conducted to explore the expression of apoptotic molecules related to death receptor and endoplasmic reticulum in the jejunal cells of chickens exposed to AFB ${ }_{1}$ diet for 3 weeks. Total of 144 one-day-old chickens was randomly divided into two groups, namely control group (containing $0 \mathbf{~ m g} / \mathbf{~ k g}$ $A F B_{1}$ ) and $A F B_{1}$ group (containing $0.6 \mathrm{mg} / \mathrm{kg} \mathrm{AFB}_{1}$ ). Histopathological observation and microscopic quantitative analysis revealed morphological changes in the jejunum such as the shedding of the mucosal epithelial cells in the apical region of villi along with the decrease of villus height, villus area and villus/crypt ratio in the AFB ${ }_{1}$ group. Both TUNEL and flow cytometry assays showed that AFB $_{1}$ intake induced excessive apoptosis of jejunal cells. Quantitative real-time PCR test displayed the general upregulation of death receptors (FAS, FASL, TNF-a and TNF-R1), endoplasmic reticulum signals (GRP78 and GRP94) as well as initiator and executioner caspases (CASPASE-10, CASPASE-8 and CASPASE-3) in the jejunum of AFB $_{1}$-intoxicated chickens. It's the first study demonstrating that $\mathrm{AFB}_{1}$ induced apoptosis of chickens' jejunum accompanied by the alteration of death receptor and endoplasmic reticulum molecule expression.

\section{INTRODUCTION}

Aflatoxins are the secondary metabolites of Aspergillus flavus and Aspergillus parasiticus. In humid areas, aflatoxins have the highest incidence in food and feed. So far, more than 20 kinds of aflatoxins have been isolated, including aflatoxin $B_{1}, B_{2}, G_{1}, G_{2}$ and so on [1]. Of these toxins, aflatoxin $\mathrm{B}_{1}\left(\mathrm{AFB}_{1}\right)$ is the most commonly encountered and is supposed to have higher toxicity than other aflatoxins [2]. International Agency 
for Research on Cancer (IARC) has produced sufficient evidences of carcinogenicity of $\mathrm{AFB}_{1}$ and classified it as a Group I human carcinogen [3]. Up to now, the hepatotoxic, carcinogenic, genotoxic, immunotoxic and other detrimental effects of $\mathrm{AFB}_{1}$ in many animal species including humans have been well documented [4-6].

Apoptosis is the process of programmed degradation and death, which aims to eliminate abnormal, senescent and harmful cells in the body, however, may also occurs as a response to various environmental stimuli including toxicity. Available information have shown that $\mathrm{AFB}_{1}$ worked as a direct or indirect initiator as well as promoter of apoptotic process $[7,8]$. For instances, AFB caused apoptosis of hepatocytes [7,9], thymocytes [10], splenocytes [11], bronchial epithelial cells [12], jejunal mucosal cells [13] and the bursa of Fabricius cells [14].

The gastrointestinal tract is responsible for digestion and absorption of food components [6]. As part of the small intestine, the jejunum accounts for a long part in small intestine and has a strong ability for absorption. Epithelium cells in the small intestine have a high turnover, and apoptosis is quite important for controlling the majority of intestinal epithelial cell loss [15-17]. Our early study showed that $0.3 \mathrm{mg} / \mathrm{kg} \mathrm{AFB}$ in the chickens' diet caused alteration of BAX, BCL-2, and CASPASE-3 expressions involved in apoptosis related to mitochondrial pathway in chickens' jejunum [13]. It is well known that there are three key regulatory molecules involved in apoptosis: mitochondria, death receptor and endoplasmic reticulum (ER) signals [18]. However, the expression of death receptor and ER molecules in the jejunum of $\mathrm{AFB}_{1-}$ intoxicated chickens have not been reported.

Therefore, the objectives of this study were to explore the expression of apoptotic molecules related to death receptor and endoplasmic reticulum in the jejunal cells by using a broiler model, based on the histopathological observation, microscopic quantitative analysis, TUNEL assay, along with flow cytometry and quantitative real-time PCR test. The results from the present study would provide a reference for the further study of the apopototic mechanism induced by $\mathrm{AFB}_{1}$ in jejunum, and may be helpful in bringing down the toxigenic potential of $\mathrm{AFB}_{1}$.

\section{RESULTS}

\section{Pathological observation and microscopic quantitative analysis}

Pathological observation showed that the mucosal epithelial cells in the apical region of villi were obviously shedding in the $\mathrm{AFB}_{1}$ group at 7, 14 and 21 days of age when compared with the control group (Figure 1a1b). Microscopic quantitative analysis revealed that the villus heights, villus areas and villus/crypt ratios of the $\mathrm{AFB}_{1}$ group were significantly decreased $(\mathrm{p}<0.05$ or $\mathrm{p}<0.01$ ), whereas the crypt depths of the $\mathrm{AFB}_{1}$ group were significantly increased when compared with those of the control group during the experiment $(\mathrm{p}<0.01)$ (Figure 1c-1f).

\section{The jejunal cell apoptosis by flow cytometry assay}

The percentage of apoptotic cells was quantitatively detected by flow cytometry. Apoptotic cell counts were measured by detecting the total percentage of early (Annexin-V positive and PI negative) and late (both Annexin-V and PI positive) apoptotic cells. When compared with the control group, the percentages of apoptotic cells of the jejunal cells in the $\mathrm{AFB}_{1}$ group were significantly increased at 7,14 and 21 days of age $(\mathrm{p}<0.01)$ (Figure 2a-2c).

\section{The jejunal cell apoptosis by TUNEL assay}

TUNEL assay demonstrated that the nuclei of TUNEL-positive cells were stained brown in two groups (Figure 3a-3b). These positive cells were mainly distributed in the apical region of villus. Compared with the control group, more TUNEL-positive cells were observed in the AFB group (Figure $3 \mathrm{a}-3 \mathrm{~b}$ ). Furthermore, microscopic quantitative analysis revealed that both the number and integrated optical density of TUNEL-positive cells in the $\mathrm{AFB}_{1}$ group were significantly increased at 7 , 14 , and 21 days of age, in comparison to the control group (Figure 3c-3d).

\section{Expression levels of apoptotic regulatory mRNAs in the jejunal cells by qRT-PCR}

qRT-PCR analysis showed that the expression levels of FAS, FASL, CASPASE- 8 and CASPASE- 3 mRNAs were significantly increased in the $\mathrm{AFB}_{1}$ group at 7,14 and 21 days of age $(p<0.05$ or $p<0.01)$ when compared with the control group (Figure 4). The expression levels of TNF- $\alpha$, TNF-R1 and CASPASE-10 mRNAs in the AFB group were significantly higher than those in the control group ( $\mathrm{p}<0.01)$ except for 7 days of age when these values were significantly lower than those in the control group $(\mathrm{p}<0.01)$ (Figure 4). Furthermore, compared with the control group, the expression levels of GRP78 and GRP94 mRNAs in the $\mathrm{AFB}_{1}$ group were significantly increased at 7,14 and 21 days of age $(\mathrm{p}<0.01)$ (Figure 5).

\section{DISCUSSION}

The small intestinal epithelium is a rapidly renewing tissue, in which cells are lost from the villus into the gut lumen and are generally replaced at an equal rate by the proliferation of cells in the crypts [16]. The intestinal villus is to enlarge the absorptive areas and to promote digestion and absorption. Thus, the measurement of the villus height, 
crypt depth, and villus height to crypt depth ratio is a wellknown way to investigate the intestinal function [19]. However, measuring the villus height by itself does not take into account the variations which may occur because of variational villus diameter. To avoid this, in the present study the villus area was also measured. Furthermore, it has been shown that apoptosis also plays an important role in the villus growth $[15-17,20,21]$. TUNEL assay can identify DNA fragmentation and examine the topographic distribution of apoptotic cells. Measuring the number and integrated optical density of TUNEL-positive reaction are the microscopic quantitative analyses to evaluate apoptotic level under microscope. Moreover, flow cytometry assay is an effective way to detect early and late stages of apoptotic cells. Our present results showed that AFB induced histopathological injury of jejunum including the shedding of the absorptive cells in the villus tip and the reduction of the villus height, villus area and villus height/ crypt ratio, and caused excessive apoptosis based on the TUNEL and flow cytometry assays, in line with our early report [22]. These results also indicated that the increased apoptosis and the shedding of the absorptive cells should be responsible for the retarded villus growth of jejunum invoked by $\mathrm{AFB}_{1}$.

Apoptosis is a highly regulated cell death program and is triggered through the mitochondria, death receptor and ER pathways. Early study has shown that the mitochondria pathway including BCL-2 and
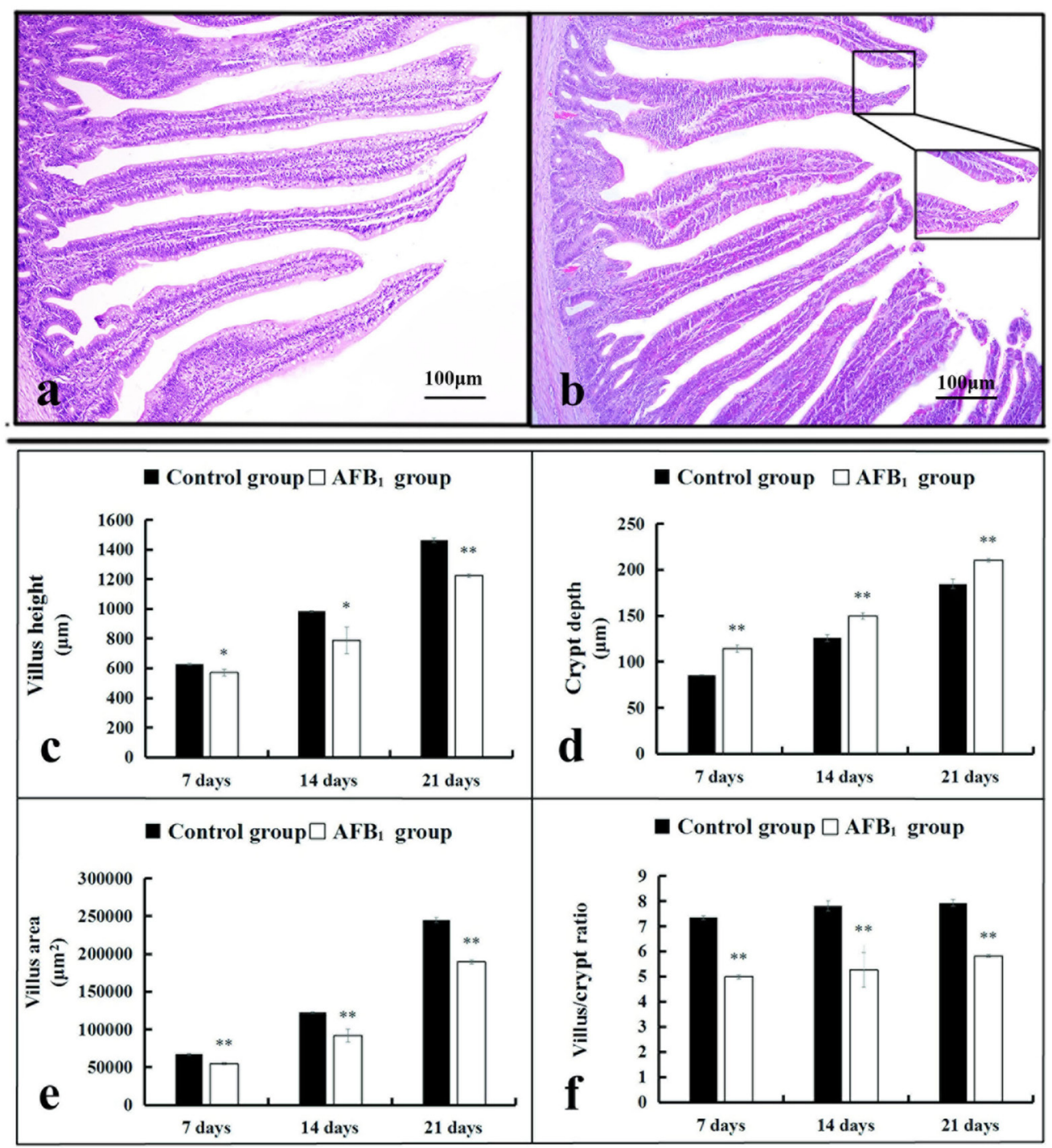

Figure 1: The histological structure of jejunum and the values of microscopic quantitative analysis. (a-b) The histological structure of jejunum at 14 days of age (HE staining, scale bar: $100 \mu \mathrm{m}$ ), (a) control group; (b) AFB group. (c-f) The values of microscopic quantitative analysis, c-f: the values of villus height, crypt depth, villus area and villus/crypt ratio, respectively.

Note: data are presented with the means \pm standard deviation $(\mathrm{n}=6) .{ }^{*} p<0.05,{ }^{* *} p<0.01$ compared with the control group. 
BAX genes were related to the excessive apoptosis of jejunum provoked by $\mathrm{AFB}_{1}$ [13]. To fully understand the alteration of $\mathrm{AFB}_{1}$-induced apoptotic associated genes in the jejunum, the expression of death receptor and ER molecules was further explored.
The death receptor pathway can be induced by the activation of death receptors including FAS, FASL, TNF- $\alpha$, TNF-R1 and CASPASES. FAS is a $45-\mathrm{kD}$ type I membrane receptor that is a member of the tumor necrosis factor family of surface receptors $[23,24]$. FASL is a
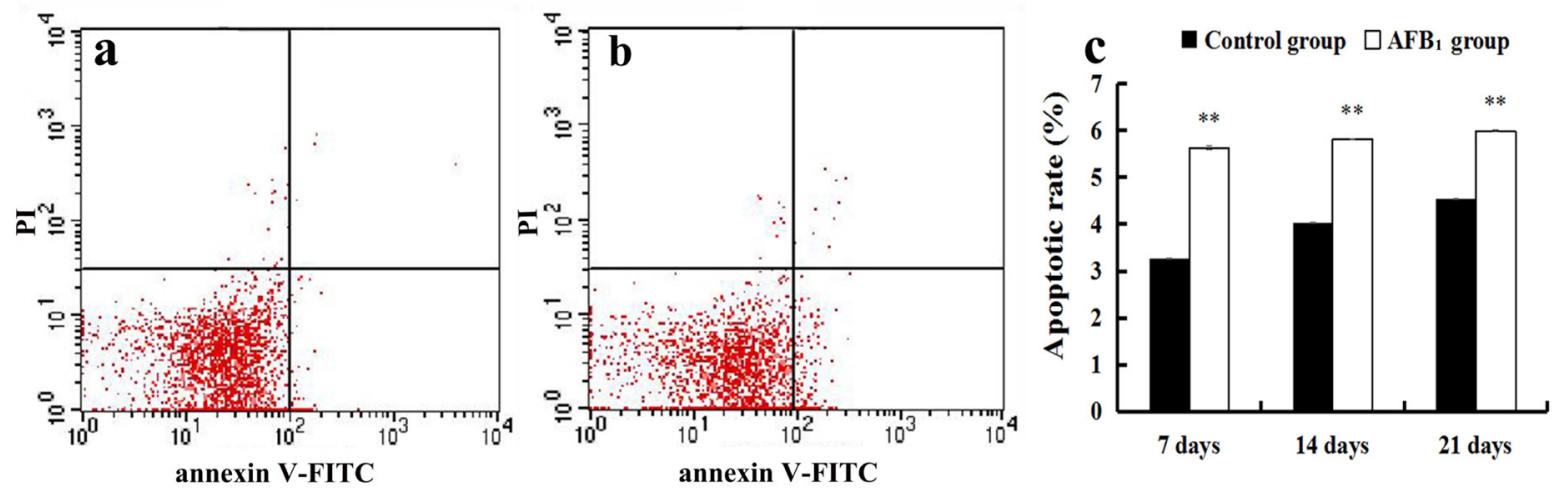

Figure 2: The jejunal cell apoptosis by flow cytometry assay. (a-b) Scattergram of apoptotic jejunal cells obtained by flow cytometry assay at 21 days of age, (a) control group; (b) AFB group. (c) Apoptotic rates by flow cytometry assay.

Note: data are presented with the means \pm standard deviation $(\mathrm{n}=6) .{ }^{* *} p<0.01$ compared with the control group.

\section{Control group}

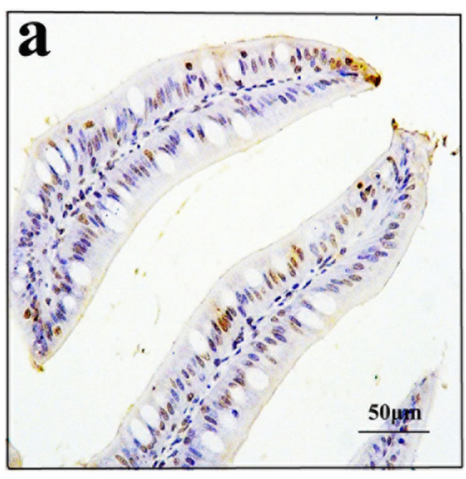

$\mathrm{AFB}_{1}$ group

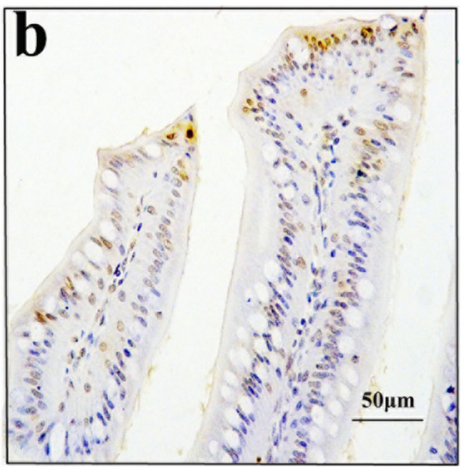

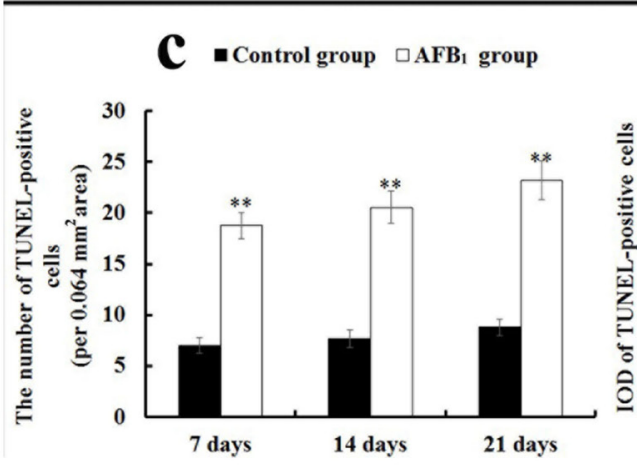

d - Control group $\square \mathrm{AFB}_{1}$ group

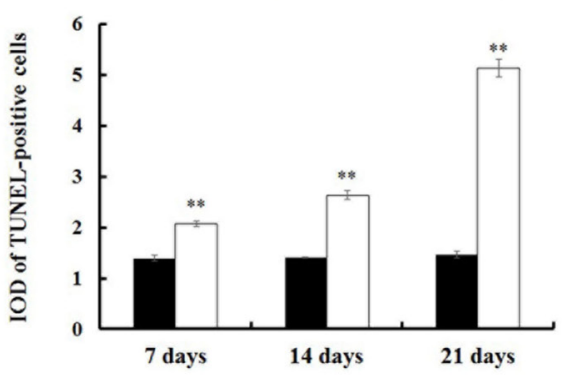

Figure 3: The jejunal cell apoptosis by TUNEL assay. (a-b) TUNEL-positive cells in the apical regions of jejunal villi at 21 days of age (TUNEL assay, scale bar: $50 \mu \mathrm{m}$ ), (a) control group; (b) AFB 1 group. (c) The number of TUNEL-positive cells. (d) The integrated optical density (IOD) of TUNEL-positive cells.

Note: data are presented with the means \pm standard deviation $(\mathrm{n}=6) .{ }^{* *} p<0.01$ compared with the control group. 
37-kD type II membrane glycoprotein that belongs to a member of the tumor necrosis factor family of cytokines [25]. Trimerization of the FAS receptor by FAS ligand results in activation of CASPASE- 8 and subsequently stimulates the activation of down-stream CASPASES, including CASPASE-3, leading to cell death [26]. TNF- $\alpha$, a pleiotropic proinflammatory cytokine, has a role in inducing cell apoptosis. TNF- $\alpha$ exerts its biological activity by binding to type 1 and type 2 receptors (TNF-R1 and TNF-R2). TNFRs belong to a large family of nerve growth factor receptors/TNFRs [27-29]. TNF-R1 is a transmembrane receptor with one to five cysteine-rich repeats in their extracellular domains and a common deathdomain (DD) in their cytoplasmic tail [30]. Upon ligation with TNF- $\alpha$, TNF-R1 undergoes trimerization of its receptor. TNF-R-associated death domain (TRADD), which in turn recruits another adapter molecule, the Fas-associated death domain (FADD). FADD recruits PROCASPASE-8 by protein-protein interaction via homologous death effector domain (DED) to form a death inducing signal complex (DISC) [31, 32]. During DISC formation, PROCASPASE- 8 is autolytically cleaved to yield active CASPASE-8. Active CASPASE-8 is rapidly released from the DISC to cytoplasm and serves as an enzyme for downstream effector CASPASE-3, CASPASE-6, and CASPASE-7. CASPASE-10 shares homologous DEDs with CASPASE-8, suggesting that CASPASE-10 may also function by interacting with death

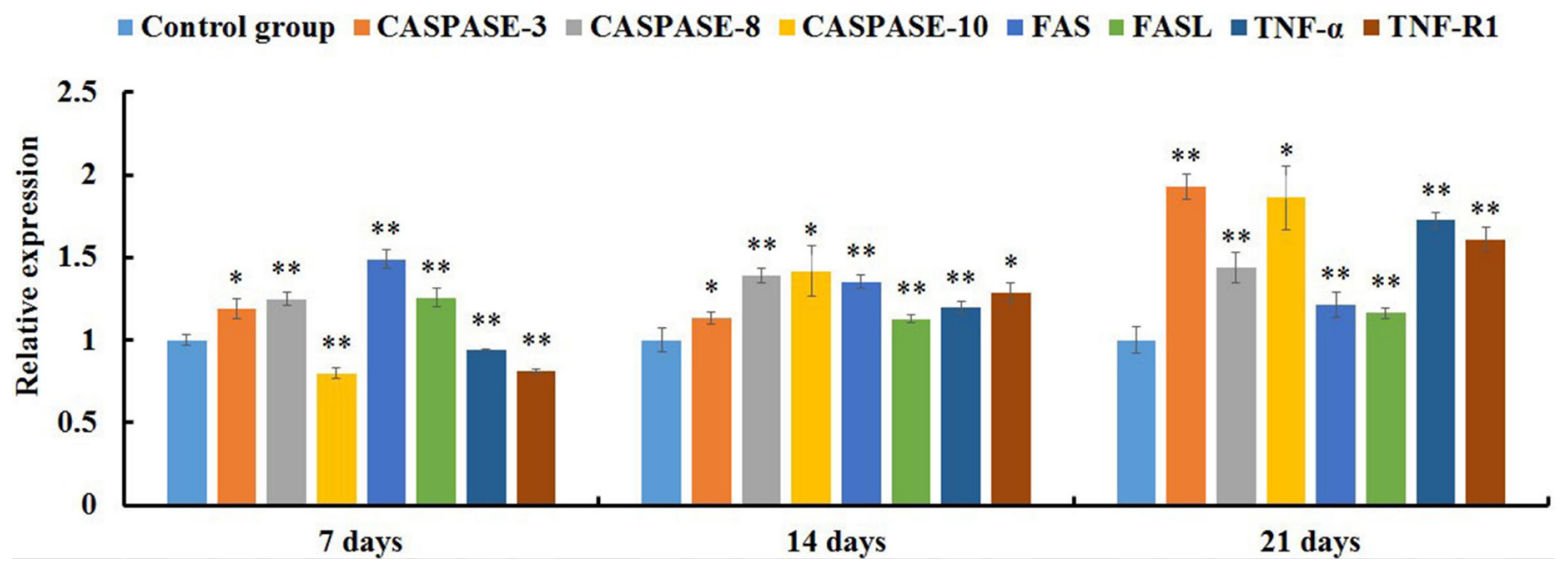

Figure 4: The expression levels of mRNAs involved in the death receptor pathway of the jejunal cell apoptosis of the $A_{F} B_{1}$-fed chicken and expressed as fold change relative to the control group.

Note: data are presented with the means \pm standard deviation $(\mathrm{n}=6) .{ }^{*} p<0.05,{ }^{* *} p<0.01$ compared with the control group.

\section{Control group $\square \operatorname{grp94} \square \operatorname{grp78}$}

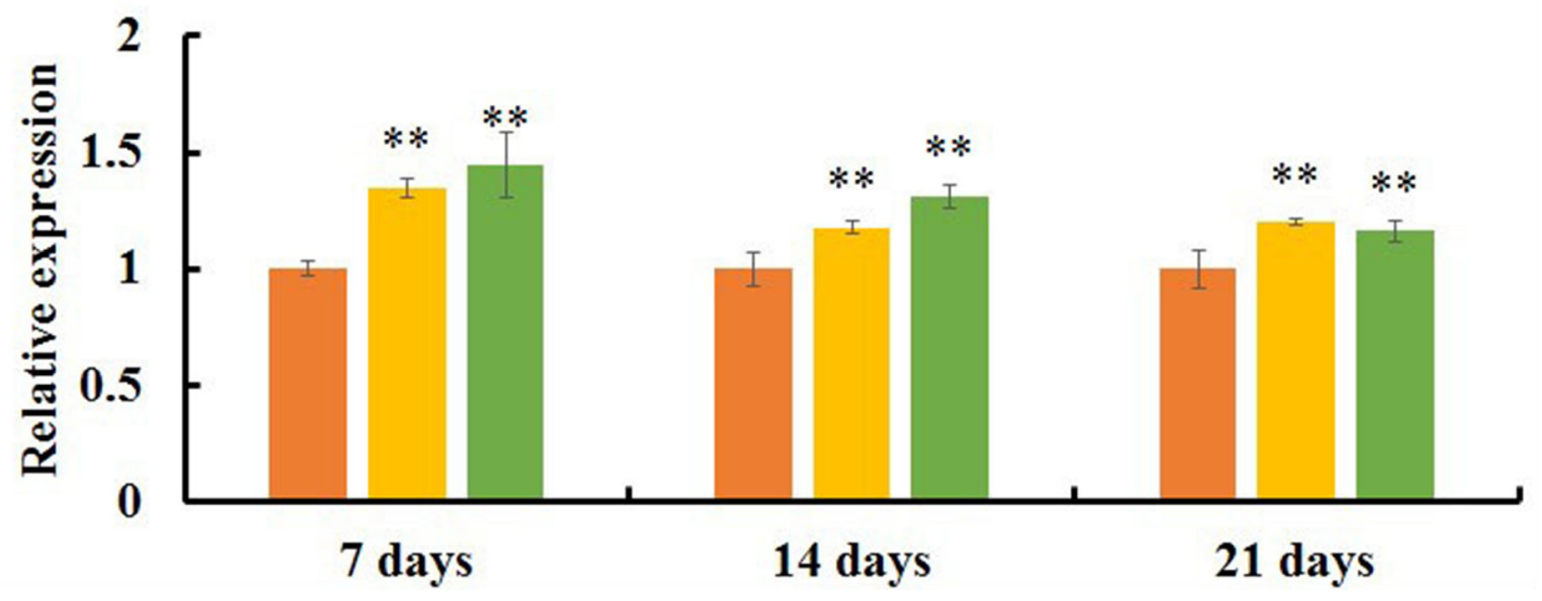

Figure 5: The expression levels of mRNAs involved in the ER pathway of the jejunal cell apoptosis of the $A_{F B}$-fed chicken and expressed as fold change relative to the control group.

Note: data are presented with the means \pm standard deviation $(\mathrm{n}=6) .{ }^{*} p<0.05,{ }^{* *} p<0.01$ compared with the control group. 
Table 1: Primer sequences, corresponding accession numbers and sizes of the amplification products

\begin{tabular}{|c|c|c|c|c|}
\hline Gene & Primer & Sequences(5'-3') & Product size(bp) & Accession number \\
\hline \multirow{2}{*}{ CASPASE-3 } & $\mathrm{F}$ & TGGCCCTCTTGAACTGAAAG & \multirow{2}{*}{139} & \multirow{2}{*}{ NM_204725 } \\
\hline & $\mathrm{R}$ & TCCACTGTCTGCTTCAATACC & & \\
\hline \multirow{2}{*}{ CASPASE-8 } & $\mathrm{F}$ & GTCTCCGTTCAGGTATCTGCT & \multirow{2}{*}{143} & \multirow{2}{*}{ NM_204592 } \\
\hline & $\mathrm{R}$ & TCTCAATGAAAACGTCCGGC & & \\
\hline \multirow{2}{*}{ CASPASE-10 } & $\mathrm{F}$ & CTGGGGGCTCCAAAAGTCC & \multirow{2}{*}{204} & \multirow{2}{*}{ XM_421936 } \\
\hline & $\mathrm{R}$ & AAAGGGGGACAAAGCCAACA & & \\
\hline \multirow{2}{*}{ FAS } & $\mathrm{F}$ & TCCACCTGCTCCTCGTCATT & \multirow{2}{*}{78} & \multirow{2}{*}{ NM_001199487 } \\
\hline & $\mathrm{R}$ & GTGCAGTGTGTGTGGGAACT & & \\
\hline \multirow{2}{*}{ FASL } & $\mathrm{F}$ & GGCATTCAGTACCGTGACCA & \multirow{2}{*}{78} & \multirow{2}{*}{ NM_001031559 } \\
\hline & $\mathrm{R}$ & CCGGAAGAGCACATTGGAGT & & \\
\hline \multirow{2}{*}{ GRP78 } & $\mathrm{F}$ & GGTGTTGCTTGATGTGTGTCC & \multirow{2}{*}{134} & \multirow{2}{*}{ NM_205491 } \\
\hline & $\mathrm{R}$ & GCTGATTGTCAGAAGCTGTGG & & \\
\hline \multirow{2}{*}{ GRP94 } & $\mathrm{F}$ & TGACCTGGATGCAAAGGTGGA & \multirow{2}{*}{250} & \multirow{2}{*}{ NM_204289 } \\
\hline & $\mathrm{R}$ & TTAAACCCCACACCATCCСТCAAC & & \\
\hline \multirow{2}{*}{ TNF- $\alpha$} & $\mathrm{F}$ & TCAGACCAGATGGGAAGGGA & \multirow{2}{*}{127} & \multirow{2}{*}{ AY765397 } \\
\hline & $\mathrm{R}$ & ACTGGGCGGTCATAGAACAG & & \\
\hline \multirow{2}{*}{ TNF-R1 } & $\mathrm{F}$ & CCTGTCTGTCTTCCCTGTCC & \multirow{2}{*}{120} & \multirow{2}{*}{ NM_001030779 } \\
\hline & $\mathrm{R}$ & GGTGCATGGGGTCTTTTCTA & & \\
\hline \multirow{2}{*}{$\beta$-actin } & $\mathrm{F}$ & TGCTGTGTTCCCATCTATCG & \multirow{2}{*}{178} & \multirow{2}{*}{ L08165 } \\
\hline & $\mathrm{R}$ & TTGGTGACAATACCGTGTTCA & & \\
\hline
\end{tabular}

receptors [33]. These effector CASPASES (especially CASPASE-3) cleaves a number of substrates resulting in morphologic and biochemical features of apoptosis [34, 35]. The present study demonstrated that $\mathrm{AFB}_{1}$ generally induced over expression of FAS, FASL, TNF- $\alpha$, TNF-R1 along with CASPASE-3, CASPASE-8 and CASPASE-10 mRNAs in the jejunum, suggesting that the death receptor molecules may involve in the excessive apoptosis of jejunal cells. Similar results were also revealed in the apoptosis of hepatocytes and thymocytes of chicken provoked by $\mathrm{AFB}_{1}[36,37]$. Contrary to the above results, the expression levels of FAS, FASL, FADD, CASPASE-8 and CASPASE-10 mRNAs of the bursa of Fabricius cells in the $\mathrm{AFB}_{1}$ group were not significantly different from those in the control group, indicating that the death receptor pathway may not contribute to the excessive cell death of the bursa of Fabricius cells induced by $\mathrm{AFB}_{1}$ [14]. Thus, the signaling pathways involved in the $\mathrm{AFB}_{1}$-caused apoptosis were not conclusive, which might be attributed to the different tissues or cells.

In the ER pathway, apoptosis mainly occurs through the ER stress. GRP78 and GRP94 (Glucose Regulated Protein 78 and $94 \mathrm{kDa}$ ) are heat shock protein family molecular chaperones that are found in the lumen of the ER. They are essential regulators of ER function due to their function in protein translocation, folding and assembly, targeting misfolded proteins for degradation, $\mathrm{ER} \mathrm{Ca}^{2+}$ binding and controlling the initiation of ER stress sensors [38]. ER stress is a phenomenon that develops either due to accumulation of unfolded or misfolded proteins within the ER or a $\mathrm{Ca}^{2+}$ store depletion [39]. Accumulation of unfolded proteins in the lumen of the ER induce unfolded protein response (UPR). During this process, the molecular chaperones (such as GRP78, GRP94) are activated and their expressions maintain proteins folding and eliminate the misfolded proteins. If the cells do not deal with accumulated misfolded proteins, a long term ER stress triggers apoptosis by recruiting the proapoptotic members of the BCL-2 family to the ER surface, and activating CASPASE-12, finally activating CASPASE-3 $[39,40]$. Therefore, GRP78 and GRP94 play an important role in the cell apoptosis triggered by the ER pathway. In the present study, the expression levels of GRP78 and GRP94 mRNAs were both significantly up-regulated in the $\mathrm{AFB}_{1}$ group when compared with the control group. Furthermore, our early study has 
demonstrated that $\mathrm{AFB}_{1}$ could induce the up-regulation of BAX mRNA expression and down-regulation of BCL-2 mRNA expression associated with the decrease of BCL-2/BAX ratio in the broilers' jejunum [13]. Thus, it is tempting to speculate that the ER molecules may be involved in the $\mathrm{AFB}_{1}$-induced excessive jejunal apoptosis. This is in line with the report in the bursa of Fabricius cells [14]. However, contradictory results showed that the ER pathway may not involve in the $\mathrm{AFB}_{1}$-induced apoptosis of thymocytes [37]. This is also confirmed that the apoptotic signaling pathways provoked by $\mathrm{AFB}_{1}$ may vary depending on different tissues.

\section{CONCLUSION}

It is concluded that $0.6 \mathrm{mg} / \mathrm{kg} \mathrm{AFB}$ in the diet could cause histopathological changes and induce apoptosis in the jejunal cells of broilers, which was accompanied by the general increase of FAS, FASL, TNF- $\alpha$, TNF-R1, CASPASE-3, CASPASE-8, CASPASE-10, GRP78 and GRP94 mRNAs expression.

\section{MATERIALS AND METHODS}

\section{Experimental diet}

Total of 144 one-day-old healthy Cobb chicken broilers was purchased from Chia Tai Group (Wenjiang, Sichuan, China), and randomly divided into control group (0 mg/kg $\mathrm{AFB}_{1}$ of basal diet) and AFB group $(0.6 \mathrm{mg} /$ $\mathrm{kg} \mathrm{AFB}_{1}$ of basal diet) with three replicates per group and 24 birds per replicate. $\mathrm{AFB}_{1}$ was purchased from Sigma-Aldrich (USA, A6636). The basal diet, namely the control diet, was formulated according to National Research Council (NRC, 1994) [41] and Chinese Feeding Standard of Chicken (NY/ T33-2004) recommendations. The $\mathrm{AFB}_{1}$-contaminated diet was made, according to the method described by Kaoud [42]. Briefly, $27 \mathrm{mg}$ $\mathrm{AFB}_{1}$ was dissolved into $30 \mathrm{ml}$ methanol, then the $30 \mathrm{ml}$ mixture was added into $45 \mathrm{~kg}$ corn-soybean basal diet to make up the $\mathrm{AFB}_{1}$-contaminated diet which contained $0.6 \mathrm{mg} / \mathrm{kg} \mathrm{AFB}_{1}$. The equivalent methanol was added into corn-soybean basal diet to formulate control diet. Then the methanol of diets was evaporated at $98^{\circ} \mathrm{F}$ $\left(37^{\circ} \mathrm{C}\right)$. The $\mathrm{AFB}_{1}$ concentration was analyzed by HPLC (Waters, Milford, MA, USA) with fluorescence detection (Waters, Model 2475, Milford, MA, USA), and the AFB concentration was determined as $<0.001 \mathrm{mg} / \mathrm{kg}$ and 0.601 $\mathrm{mg} / \mathrm{kg}$ in the control diet and $\mathrm{AFB}_{1}$ diet, respectively. Chickens were fed in cages with electrically heated units and provided with water as well as aforementioned diet ad libitum for 21 days. The animal protocols used in this work and all procedures of the experiment were performed based on the laws and guidelines of Sichuan Agricultural University Animal Care and Use Committee (Approval No: 2012-024).

\section{Histopathological observation and microscopic quantitative analysis}

During the period of experiment, six broilers in each group were randomly chosen and euthanized at 7, 14 and 21 days of age. And jejunum (the midpoint between the bile duct entry and Meckel's diverticulum) was immediately fixed in 4\% paraformaldehyde. After $24 \mathrm{~h}$ for fixation, tissues were dehydrated in alcohol, embedded by paraffin, sectioned at $5 \mu \mathrm{m}$, and stained with haematoxylin and eosin (HE) for histological observation. The histological structures of the tissues were observed and photographed with a digital camera (Nikon, DS-Ril, Japan). Microscopic quantitative analysis was carried out as follows: altogether ten measurements were taken per broiler for each parameter in the jejunum stained with HE using Image-Pro Plus 5.1 (USA) image analysis software. The following parameters were determined: villus height (the length from the top of the villus to the crypt mouth), villus area the villus height multiplying villus width (the width of the middle of the villus) , crypt depth (the length from the crypt mouth to the crypt base following the crypt lumen) and ratio of the villus height and crypt depth (villus/crypt).

\section{Cell apoptosis analysis by flow cytometry}

At 7, 14, and 21 days of the experiment, six broilers in each group were euthanized, and jejuna were sampled from each chicken to determine the percentage of apoptotic cells by flow cytometer, similar to the method reported by Chen [43]. Briefly, the dissected jejuna were thereupon homogenized to form a cell suspension and filtered, then the cells were washed and resuspended in phosphate buffer at a concentration of $1 \times 10^{6}$ cells $/ \mathrm{mL}$. $5 \mu \mathrm{L}$ Annexin V-Fluorescein isothiocyanate (V-FITC) and $5 \mu \mathrm{L}$ propidium iodide (PI) were added into $100 \mu \mathrm{L}$ cell suspension, and incubated at $25^{\circ} \mathrm{C}$ for $15 \mathrm{~min}$ in the dark. $400 \mu \mathrm{L} 1 \times$ Annexin binding buffer was added to the mixture, and then the apoptotic cells were assayed by flow cytometer (BD FACSCalibur) within $1 \mathrm{~h}$. The annexin V-FITC Kit was obtained from BD Pharmingen (USA, 556547).

\section{TUNEL assay}

TUNEL assay was carried out according to the manufacturer's instruction of the Apoptosis Detection Kit (Boster Corporation). Briefly, the jejunal paraffin sections were dewaxed with $100 \%$ xylene, and rehydrated in successive changes of $100 \%, 95 \%, 85 \%$ and $75 \%$ ethanol. After endogenous peroxidase activity was quenched for 10 min in $3 \% \mathrm{H}_{2} \mathrm{O}_{2}$ with distilled water at $37{ }^{\circ} \mathrm{C}$, the sections were incubated with proteinase $\mathrm{K}$ diluted 1:200 in TBS at $37^{\circ} \mathrm{C}$ for 5-10 min in a humid chamber. A labeling mixture containing digoxin-dUTP in Terminaldeoxynucleotidyl Transferase (TdT) enzyme buffer was added to the sections 
and incubated at $37^{\circ} \mathrm{C}$ for $2 \mathrm{~h}$. After three successive washings with TBS for $2 \mathrm{~min}$, sections were covered with anti-digoxin-biotin conjugate diluted 1:100 in blocking regent and incubated for $30 \mathrm{~min}$ at $37{ }^{\circ} \mathrm{C}$. The tissues were then incubated for $1 \mathrm{~h}$ at $37^{\circ} \mathrm{C}$ with streptavidinbiotin-complex (SABC) diluted 1:100 in TBS. Labeling was visualized with 3'3'-diaminobenzidene. The sections were then counterstained with haematoxylin. For the negative control, representative sections were processed in the same way, while incubation with TdT enzyme buffer was omitted.

The number and integrated optical density (IOD) of TUNEL-positive cells were evaluated as following method. Briefly, photographs of TUNEL staining were taken with a digital microscope camera system (Nikon DS-Ri1, Japan). For each section, five fields of 0.064 $\mathrm{mm}^{2}$ from each area of the image (corresponding to five fields at $400 \times$ magnification) were analyzed using computer-assisted image-Pro Plus 5.1 (USA) image analysis software. By selecting 'colour-chosen target' in the option bar of the morphologic analysis system, all TUNEL-positive cells in the field were marked in colour. Then, 'calculating' in the option bar was selected to automatically calculate the number and IOD values.

\section{Quantitative real-time PCR (qRT-PCR) analysis}

The jejunal mucosae from six broilers in each treatment at 7,14 , and 21 days of the experiment were stored in liquid nitrogen, respectively. Adding liquid nitrogen, the jejunal mucosae were crushed with pestle to homogenize until powdery, respectively. Total RNA was extracted from the powdery of jejunal mucosae using RNAiso Plus (9108/9109, Takara, Otsu, Japan). The mRNA was then reversely transcribed into cDNA using Prim Script ${ }^{\mathrm{TM}}$ RT reagent Kit with gDNA Eraser (RR047A, Takara, Otsu, Japan). The cDNA was used as a template for quantitative real-time PCR analysis.

For qRT-PCR reactions, $25 \mu \mathrm{L}$ mixtures were made by using SYBR ${ }^{\circledR}$ Premix Ex Taq ${ }^{\text {TM }}$ II (DRR820A, Takara, Otsu, Japan), containing $12.5 \mu \mathrm{L}$ Tli RNaseH Plus, $1.0 \mu \mathrm{L}$ of forward and $1.0 \mu \mathrm{L}$ of reverse primer, $8.5 \mu \mathrm{L}$ RNAasefree water and $2 \mu \mathrm{L}$ cDNA. Reaction conditions were set to $3 \mathrm{~min}$ at $95{ }^{\circ} \mathrm{C}$ (first segment, one cycle), $10 \mathrm{~s}$ at $95^{\circ} \mathrm{C}$ and $30 \mathrm{~s}$ at Tm of a specific primer pair (second segment, 44 cycles) followed by $10 \mathrm{~s}$ at $95^{\circ} \mathrm{C}$, and $72{ }^{\circ} \mathrm{C}$ for 10 $\mathrm{s}$ (dissociation curve segment) using Thermal Cycler (C1000, BIO RAD, CA, USA). The expression of FAS, FASL, TNF- $\alpha$, TNF-R1, GRP78, GRP94, CASPASE-3, CASPASE-8 and CASPASE-10 mRNAs was analyzed, and $\beta$-actin was used as an internal control gene. Sequence of primers was obtained from GenBank of NCBI. Primers were designed with Primer 5, and synthesized by BGI Tech (Shenzhen, China) (Table 1). The control broilers responses (mRNA amount) were been as reference values for between treatments comparisons within the same control day in each week, respectively. The results were analyzed with $2^{-\Delta \Delta \mathrm{Ct}}$ calculation method [44].

\section{Statistical analysis}

The significance of difference between two groups was analyzed by variance analysis, and the results were expressed by means \pm standard deviation. The analyses were performed using the independent sample test of SPSS 20.0 software (IBM Corp, Armonk, NY, USA) for windows. Statistical significant differences were considered at $\mathrm{p}<0.05$ and markedly significant differences were considered at $\mathrm{p}<0.01$.

\section{ACKNOWLEDGMENTS}

This work was supported by the program for Changjiang scholars, the University Innovative Research Team (IRT 0848), the Education Department of Sichuan Province (2012FZ0066) and (2013FZ0072) and Huimin project of Chengdu science and technology (2016-HM0100337-SF).

\section{CONFLICTS OF INTEREST}

The authors declare no conflicts of interest.

\section{REFERENCES}

1. Abrar M, Anjum FM, Butt MS, Pasha I, Randhawa AM, Saeed F, Waqas K. Aflatoxins: biosynthesis, occurrence, toxicity, and remedies. Crit Rev Food Sci. 2013; 53:862-874.

2. Nakai VK, Rocha LDO, Gonçalez E, Fonseca H, Ortega EMM, Correa B. Distribution of fungi and aflatoxins in a stored peanut variety. Food Chem. 2008; 106:285-290.

3. International Agency for Research on Cancer. (2006). IARC monographs on the evaluation of carcinogenic risks to humans. Lyon, France: International Agency for Research on Cancer, World Health Organization.

4. Abbès S, Salah-Abbès JB, Abdel-Wahhab MA, Ouslati R. Immunotoxicological and biochemical effects of aflatoxins in rats prevented by Tunisian Montmorillonite with reference to HSCAS. Immunopharm Immunot. 2010; 32:514-522.

5. Kalpana S, Aggarwal M, Rao GS, Malik JK. Effects of aflatoxin B1 on tissue residues of enrofloxacin and its metabolite ciprofloxacin in broiler chickens. Environ Toxicol Phar. 2012; 33:121-126.

6. Yunus AW, Razzazi-Fazeli E, Bohm J. Aflatoxin B1 in affecting broiler's performance, immunity, and gastrointestinal tract: a review of history and contemporary issues. Toxins. 2011, 3:566-590. 
7. Ribeiro DH, Ferreira FL, Silva VND, Aquino S, Correa B. Effects of aflatoxin B1 and fumonisin B1 on the viability and induction of apoptosis in rat primary hepatocytes. Int J Mol Sci. 2010; 11:1944-1955.

8. Brahmi D, Bouaziz C, Ayed Y, Mansour HB, Zourgui L, Bacha H. Chemopreventive effect of cactus Opuntia ficus indica on oxidative stress and genotoxicity of aflatoxin B1. Nutr Metab. 2011; 8:73.

9. Deng SX, Tian LX, Liu FJ, Jin SJ, Liang GY, Yang HJ. Toxic effects and residue of aflatoxin B1 in tilapia (Oreochromis niloticus $\times$ O. aureus) during long-term dietary exposure. Aquaculture.2010; 307:233-240.

10. Chen K, Shu G, Peng X, Fang J, Cui H, Chen J, Wang F, Chen Z, Zuo Z, Deng J, Geng Y, Lai W. Protective role of sodium selenite on histopathological lesions, decreased T-cell subsets and increased apoptosis of thymus in broilers intoxicated with aflatoxin B1. Food Chem Toxicol. 2013; 59:446-454.

11. Wang F, Shu G, Peng X, Fang J, Chen K, Cui H, Chen Z, Zuo Z, Deng J, Geng Y, Lai W. Protective effects of sodium selenite against aflatoxin B1-induced oxidative stress and apoptosis in broiler spleen. Inter J Env Res Pub Heal. 2013; 10:2834-2844.

12. Yang XJ, Lu HY, Li ZY, Bian Q, Qiu LL, Li Z, Liu Q, Li J, Wang X, Wang S. Cytochrome P450 2A13 mediates aflatoxin B1-induced cytotoxicity and apoptosis in human bronchial epithelial cells. Toxicology. 2012; 300:138-148.

13. Peng X, Zhang S, Fang J, Cui H, Zuo Z, Deng J. Protective roles of sodium selenite against aflatoxin B1-induced apoptosis of jejunum in broilers. Inter J Env Res Pub Heal. 2014; 11:13130-13143.

14. Yuan S, Wu B, Yu Z, Fang J, Liang N, Zhou M, Huang C, Peng X. The mitochondrial and endoplasmic reticulum pathways involved in the apoptosis of bursa of Fabricius cells in broilers exposed to dietary aflatoxin B1. Oncotarget. 2014; 7:65295-65306. doi: 10.18632/oncotarget.11321.

15. Conto CD, Oevermann A, Burgener IA, Doherr MG, Blum JW. Gastrointestinal tract mucosal histomorphometry and epithelial cell proliferation and apoptosis in neonatal and adult dogs. J Anim Sci. 2010, 88:2255-2264.

16. Potten CS, Wilson JW, Booth C. Regulation and significance of apoptosis in the stem cells of the gastrointestinal epithelium. Stem Cells. 1997; 15:82-93.

17. Jones BA, Gores GJ. Physiology and pathophysiology of apoptosis in epithelial cells of the liver, pancreas, and intestine. Am J Physiol-gastr L. 1997; 273:G1174-G1188.

18. Favaloro B, Allocati N, Graziano V, Di-Ilio C, De-Laurenzi V. Role of apoptosis in disease. Aging. 2012; 4:330-349. doi: 10.18632/aging.100459.

19. Jeurissen SHM, Lewis F, Klis JDVD, Mroz Z, Rebel JMJ, Huurne AAHM. Parameters and techniques to determine intestinal health of poultry as constituted by immunity, integrity, and functionality. Curr Issues Intest Microbiol. 2002; 3:1-14.
20. Wan XL, Yang ZB, Yang WR, Jiang SZ, Zhang GG, Johnston SL, Chi F. Toxicity of increasing aflatoxin B1 concentrations from contaminated corn with or without clay adsorbent supplementation in ducklings. Poultry Sci. 2013; 92:1244-1253.

21. Applegate TJ, Schatzmayr G, Prickel K, Trohce C, Jiang Z. Effect of aflatoxin culture on intestinal function and nutrient loss in laying hens. Poultry Sci. 2009; 88:1235-1241.

22. Yin H, Jiang M, Peng X, Cui H, Zhou Y, He M, Zuo Z, Ouyang P, Fan J, Fang J. The molecular mechanism of G2/M cell cycle arrest induced by AFB1 in the jejunum. Oncotarget. 2016; 7:35592-35606. doi: 10.18632/ oncotarget.9594.

23. Itoh N, Nagata S. A novel protein domain required for apoptosis. Mutational analysis of human fas antigen. J Biol Chem. 1993; 268:10932-10937.

24. Itoh N, Yonehara S, Ishii A, Yonehara M, Mizushima S, Sameshima M, Hase A, Seto Y, Nagata S. The polypeptide encoded by the cDNA for human cell surface antigen Fas can mediate apoptosis. Cell. 1991; 66:233-243.

25. Suda T, Takahashi T, Golstein P, Nagata S. Molecular cloning and expression of the Fas ligand, a novel member of the tumor necrosis factor family. Cell. 1993; 75:1169-1178.

26. Waring P, Müllbacher A. Cell death induced by the Fas/ Fas ligand pathway and its role in pathology. Immunol Cell Biol. 1999; 77:312-317.

27. Rothe J, Gehr G, Loetscher H, Lesslauer W. Tumor necrosis factor receptors structure and function. Immunol Res. 1992; 11:81-90.

28. Wallach D. Suicide by order: some open questions about the cell-killing activities of the TNF ligand and receptor families. Cytokine Growth F R. 1996; 7:211-221.

29. Wallach D, Boldin M, Varfolomeev E, Beyaert R, Vandenabeele P, Fiers W. Cell death induction by receptors of the TNF family: towards a molecular understanding. Febs Lett. 1997; 410:96-106.

30. Thomas B, Grell M, Pfizenmaier K, Scheurich P. Identification of a $60-\mathrm{kDa}$ tumor necrosis factor (TNF) receptor as the major signaltransducing component in TNF responses. J Exp Med. 1990; 172:1019-1023.

31. Yuan J. Transducing signals of life and death. Curr Opin Cell Biol. 1997; 9:247-251.

32. Aggarwal S, Gollapudi S, Gupta S. Increased TNF- $\alpha-$ induced apoptosis in lymphocytes from aged humans: changes in TNF- $\alpha$ receptor expression and activation of caspases. J Immunol. 1999; 162:2154-2161.

33. Wang J, Chun HJ, Wong W, Spencer DM, Lenardo MJ. Caspase-10 is an initiator caspase in death receptor signaling. P Natl Acad Sci USA. 2001; 98:13884-13888.

34. Gupta S. Molecular steps of death receptor and mitochondrial pathways of apoptosis. Life Sci. 2001; 69:2957-2964. 
35. Darnay BG, Aggarwal BB. Early events in TNF signaling: a story of associations and dissociations. J Leukocyte Biol. 1997; 61:559-566.

36. Mughal MJ, Peng X, Zhou Y, Fang J. Aflatoxin B1 invokes apoptosis via death receptor pathway in hepatocytes. Oncotarget. 2017; 8:8239-8249. doi: 10.18632/ oncotarget.14158.

37. Peng X, Yu Z, Liang N, Chi X, Li X, Jiang M, Fang J, Cui H, Lai W, Zhou Y, Zhou S. The mitochondrial and death receptor pathways involved in the thymocytes apoptosis induced by aflatoxin B1. Oncotarget. 2016; 7:12222-12234. doi: 10.18632/oncotarget.7731.

38. Nami B, Ghasemi-Dizgah A, Vaseghi A. Overexpression of molecular chaperons grp78 and grp94 in CD44 (hi)/ CD24 (lo) breast cancer stem cells. Bioimpacts Bi. 2016; 6:105-110

39. Hammadi M, Oulidi A, Gackière F, Katsogiannou M, Slomianny C, Roudbaraki M, Dewailly E, Delcourt P, Lepage G, Lotteau S, Ducreux S, Prevarskaya N, Coppenolle FV. Modulation of ER stress and apoptosis by endoplasmic reticulum calcium leak via translocon during unfolded protein response: involvement of GRP78. Faseb J. 2013; 27:1600-1609.

40. Morishima N, Nakanishi K, Takenouchi H, Takehiko $\mathrm{S}$, Yukuto Y. An endoplasmic reticulum stress-specific caspase cascade in apoptosis cytochrome c-independent activation of caspase- 9 by caspase-12. J Biol Chem. 2002; 277:34287-34294.

41. Dale N. National research council nutrient requirements of poultry-ninth revised edition (1994). J Appl Poultry Res. 1994; 3:101.

42. Kaoud HA. Innovative methods for the amelioration of aflatoxin (afb1) effect in broiler chicks. Sci J Appl Res. 2012; 1:16-21.

43. Chen T, Cui H, Cui Y, Bai C, Gong T, Peng X. Cell-cycle blockage associated with increased apoptotic cells in the thymus of chickens fed on diets high in fluorine. Hum Exp Toxicol. 2011; 30:685-692.

44. Livak KJ, Schmittgen TD. Analysis of relative gene expression data using real-time quantitative PCR and the $2-\Delta \Delta C$ T method. Methods. 2001; 25:402-408. 